\title{
Psoriasin promotes invasion, aggregation and survival of pancreatic cancer cells; association with disease progression
}

\author{
YING LIU $^{1,2}$, CARLY BUNSTON ${ }^{1}$, NICHOLAS HODSON ${ }^{1}$, JEYNA RESAUL ${ }^{1}$, PING-HUI SUN ${ }^{1}$, \\ SHUO CAI $^{1}$, GANG CHEN ${ }^{1}$, YANAN GU ${ }^{1}$, LUCY K. SATHERLEY ${ }^{1}$, DAVID C. BOSANQUET ${ }^{1}$, \\ BILAL AL-SARIREH $^{3}$, XIUYUN TIAN ${ }^{4}$, CHUNYI HAO $^{4}$, WEN G. JIANG ${ }^{1}$ and LIN YE ${ }^{1}$ \\ ${ }^{1}$ Metastasis and Angiogenesis Research Group, Cardiff China Medical Research Collaborative, \\ Division of Cancer and Genetics, Cardiff University School of Medicine, Cardiff, \\ CF14 4XN, UK; ${ }^{2}$ Institute of Pathology and Southwest Cancer Center, \\ Southwest Hospital, Third Military Medical University, Chongqing 400037, P.R. China; \\ ${ }^{3}$ Department of Surgery, Morriston Hospital, ABM University Health Board, Swansea, \\ SA6 6NL, UK; ${ }^{4}$ Key Laboratory of Carcinogenesis and Translational Research \\ (Ministry of Education/Beijing), Department of Hepato-Pancreato-Biliary Surgery, \\ Peking University Cancer Hospital and Institute, Beijing 100142, P.R. China
}

Received August 12, 2016; Accepted February 28, 2017

DOI: $10.3892 /$ ijo.2017.3953

\begin{abstract}
Psoriasin (S100A7) is an 11-kDa small calcium binding protein initially isolated from psoriatic skin lesions. It belongs to the S100 family of proteins which play an important role in a range of cell functions including proliferation, differentiation, migration and apoptosis. Aberrant Psoriasin expression has been implicated in a range of cancers and is often associated with poor prognosis. This study examined the role of Psoriasin on pancreatic cancer cell functions and the implication in progression of the disease. Expression of Psoriasin was determined in a cohort of pancreatic tissues comprised of 126 pancreatic tumours and 114 adjacent non-tumour pancreatic tissues. Knockdown and overexpression of Psoriasin in pancreatic cancer cells was performed using specifically constructed plasmids, which either had anti-Psoriasin ribozyme transgene or the full length human Psoriasin coding sequence. Psoriasin knockdown and overexpression was verified using conventional RT-PCR and qPCR. The effect of manipulating Psoriasin expression on pancreatic cancer cell functions was assessed using several in vitro cell function assays. Local invasive pancreatic cancers extended beyond the pancreas expressed higher levels of Psoriasin
\end{abstract}

Correspondence to: Dr Lin Ye, Metastasis and Angiogenesis Research Group, Cardiff China Medical Research Collaborative, Institute of Cancer and Genetics, Cardiff University School of Medicine, GF55 Henry Wellcome Building, Heath Park, Cardiff, CF14 4XN, UK

E-mail: yel@cf.ac.uk

Key words: Psoriasin, S100A7, pancreatic cancer, adhesion, invasion, metastasis transcripts compared with the cancers confined to the pancreas. Primary tumours with distant metastases exhibited a reduced expression of Psoriasin. Psoriasin overexpression cell lines exhibited significantly increased growth and migration compared to control cells. In addition, Psoriasin overexpression resulted in increased pancreatic cancer cell invasion which was associated with upregulation of matrix metalloproteinase-2 (MMP-2) and MMP-9. Overexpression of Psoriasin also promoted aggregation and survival of pancreatic cancer cells when they lost anchorage. Taken together, higher expression of Psoriasin was associated with local invasion in pancreatic cancers. Psoriasin expression is associated with pancreatic cancer cell growth, migration, cell-matrix adhesion, and invasion via regulation of MMPs. As such, the proposed implications of Psoriasin in invasion, disease progression and as a potential therapeutic target warrant further investigation.

\section{Introduction}

Psoriasin, also known as S100A7, is a member of the $\mathrm{S} 100$ protein family of calcium binding proteins and was first identified as being overexpressed in psoriatic skin lesions (1). It is a $11.4-\mathrm{kDa}$ secretory protein encoded on chromosome 1q21, clustered alongside 16 other members of the S100 family within a region known as the epidermal differentiation complex (EDC) $(2,3)$. The S100 family encodes both cytoplasmic and secreted proteins that share EF-hand helixloop-helix domains, important for their role as calcium binding proteins (4). Psoriasin S100 proteins are widely expressed in numerous cell types localised to the cytoplasm and/or nucleus, or in some cases are secreted. Due to their role in calcium binding and signalling, they are involved in numerous cell functions including proliferation, differentiation, migration and apoptosis. 
In addition to its overexpression in psoriatic skin lesions, aberrant Psoriasin expression has been implicated in a range of human diseases including cancer. Interestingly, Psoriasin is a chemotactic factor for keratinocytes and leukocytes (5-7), and is also upregulated and excreted from cells of the epidermis during inflammation. Additionally, Psoriasin has been implicated as an antimicrobial peptide, selectively killing $E$. coli on the surface of the skin (8). Therefore, Psoriasin may be utilised, via the host immune response, as a selective chemotactic factor both in psoriasis and cancer (9).

The expression of Psoriasin during carcinogenesis has been studied in detail, and its overexpression has been linked to a number of cancers including breast (10), prostate (11), skin (12), head and neck (13), bladder (14) and lung cancer (15). It is also often associated with poor prognosis. For example in breast cancer, Psoriasin expression correlates with features of poor prognosis, including oestrogen receptor (ER) and progesterone receptor (PR) negativity, HER2 positivity, and the presence of lymphocytic infiltration (16-18). The precise role of Psoriasin in cancer remains unclear. One hypothesis links Psoriasin expression with stimulation of angiogenesis regulated by VEGF (19). In the development of breast cancer, Psoriasin regulates epidermal growth factor (EGF)-induced phosphorylation of the EGF receptor (EGFR), actin remodelling and NF- $\kappa \beta$ mediated matrix metalloproteinase-9 (MMP-9) secretion, promoting tumour development and metastasis (20). These results suggest Psoriasin plays an important role in carcinoma development.

Pancreatic cancer is the fourth leading cause of cancer deaths in Western countries and carries a very poor prognosis due to delayed diagnosis and lack of effective treatments. The majority of patients present with metastasis at diagnosis; $25 \%$ with local metastasis and $55 \%$ with regional metastasis (21). The most common sites of metastasis are the liver, followed by the peritoneum, lung and pleura, bones and adrenal glands. Outcome for patients is poor with a 5 -year survival rate of $<5 \%$ (22). In comparison to the studies of other malignancies, pancreatic cancer requires more intensive study for understanding genetic and molecular machinery which is utilised by cancerous cells during disease progression and metastasis. This study aimed to examine the role of Psoriasin in pancreatic cancer with a focus for its involvement in local invasion and distant metastasis.

\section{Materials and nethods}

Materials and cell lines. Pancreatic cell lines (MIA-PaCa-2 and PANC-1) were purchased from the American Type Culture Collection (ATCC, Rockville, MD, USA). Both cell lines are derived from primary tumours of pancreatic cancer. MIA-PaCa-2 was isolated from a pancreatic carcinoma while PANC-1 was derived from an epithelioid carcinoma of pancreas. The pancreatic cancer cells were maintained in Dulbecco's modified Eagle's medium (DMEM)-F12 medium, supplemented with $10 \%$ fetal calf serum (FCS) and antibiotics. LP-9 mesothelial cells were purchased from the Coriell Institute for Medical Research (Camden, NJ, USA) and maintained in M199 medium supplemented with 15\% FCS and antibiotics. Matrigel (BD Matrigel Basement Membrane Matrix) was obtained from BD Biosciences (Oxford, UK).
Construction of ribozyme transgenes targeting human Psoriasin and Psoriasin overexpression vectors. Anti-human Psoriasin hammerhead ribozymes were designed based on the secondary structure of the mRNA generated using Zuker's RNA Mfold program (23). The ribozymes were synthesized and cloned into pEF6/V5-His-TOPO plasmid vector (Invitrogen, Paisley, UK). The primers used for ribozyme synthesis are shown in Table I. Similarly, full-length human Psoriasin coding sequence amplified from normal human prostate tissues was cloned into the same vector. Constructed plasmids were extracted using the Genelute Plasmid Mini-Prep kit (Sigma-Aldrich, Poole, UK). Ribozyme transgenes, overexpression constructs, and control plasmids were transfected into MIA-PaCa-2 and PANC-1 cells by electroporation (Gene Pulser Xcell; Bio-Rad, Hertfordshire, UK). Stable transfectants were obtained and verified following two weeks selection using blasticidin ( $5 \mu \mathrm{g} / \mathrm{ml}$, Melford Laboratories Ltd., Suffolk, UK). The cells were then cultured in DMEM with blasticidin at a lower concentration $(0.5 \mu \mathrm{g} / \mathrm{ml})$ to maintain plasmid expression.

RNA isolation, reverse transcription-PCR $(R T-P C R)$ and quantitative PCR (qPCR). Total RNA was isolated using TRI reagent (Sigma-Aldrich). First strand cDNA synthesis was undertaken using the Precision nanoScript Reverse Transcription kit (Primer Design, Southampton, UK). PCR was performed using GoTaq Green MasterMix (Promega, Dorset, UK). Cycling conditions were as follows: $94^{\circ} \mathrm{C}$ for 5 min followed by 36 cycles of $94^{\circ} \mathrm{C}$ for $30 \mathrm{sec}, 55^{\circ} \mathrm{C}$ for $30 \mathrm{sec}$, and $72^{\circ} \mathrm{C}$ for $40 \mathrm{sec}$. This was followed by a final extension of $72^{\circ} \mathrm{C}$ for $10 \mathrm{~min}$. Products were visualised using $2 \%$ agarose gels stained with SYBR Safe (Invitrogen).

QPCR was performed using the Icycler IQ5 system (Bio-Rad, Hammel Hempsted, UK). Pancreatic cancer cell cDNA samples were examined for Psoriasin transcript expression, alongside a set of standards and negative controls. The Amplifluor system (Intergen Inc., Oxford, UK) and qPCR mastermix (Bio-Rad) were used. Psoriasin primer pairs were designed using Beacon design software (Premier Biosoft, Palo Alto, CA, USA), whereby the reverse primer contained an additional $Z$ sequence (5'-ACTGAACCTGACCGTACA) complementary to the universal $\mathrm{Z}$ probe (Intergen Inc.). Reaction conditions were as follows: $94^{\circ} \mathrm{C}$ for $12 \mathrm{~min}$, followed by 90 cycles of $94^{\circ} \mathrm{C}$ for $15 \mathrm{sec}, 55^{\circ} \mathrm{C}$ for $40 \mathrm{sec}$ and $72^{\circ} \mathrm{C}$ for $20 \mathrm{sec}$.

Quantification of Psoriasin transcripts in human pancreatic cancer. Human pancreatic tissue was collected from patients undergoing surgical resection of pancreatic tumours at the Beijing Cancer Hospital. The specimens retrieved comprised 126 pancreatic tumours and 114 along with matched adjacent normal pancreatic tissues over a period from 2002 to 2011 with follow-up information up to 2013 (median, 12 months, IQR, 6-20.5 months). The tissues were stored immediately after surgery at $-80^{\circ} \mathrm{C}$ until use. Clinicopathological factors, including age, sex, histological type, TNM stage, lymph node metastasis, distant metastases and embolism, were recorded and stored in the patient database. The protocol and procedure were reviewed and approved by the Beijing Cancer Hospital Research Ethics Committee and written consent was obtained 
Table I. Primer sequences.

\begin{tabular}{lll}
\hline Gene & \multicolumn{1}{c}{ Forward } & \multicolumn{1}{c}{ Reverse } \\
\hline Psoriasin & 5'-GAGGTCCATAATAGGCATGA & 5'-AGCAAGGACAGAAACTCAGA \\
RAGE & 5'-GATCCAGGATGAGGGGATTT & 5'-GCTACTGCTCCACCTTCTGG \\
Psoriasin (expression) & 5'-ATGAGCAACACTCAAGCTG & 5'-ACTGGCTGCCCCGGAACA \\
Psoriasin $(Q P C R)$ & 5'-TGTGACAAAAAGGGCACAAA & 5'-ACTGAACCTGACCGTACACCCAGCAAGGACA \\
& & GAAACTC \\
CK19 $(Q P C R)$ & 5'-CAGGTCCGAGGTTACTGAC & 5'-ACTGAACCTGACCGTACACCGTTTCTGCCAGT \\
& & GTGTCTTC \\
Cyclin D1 & 5'-CGGTGTCCTACTTCAAATGT & 5'-ACCTCCTCCTCCTCCTCT \\
p27 ${ }^{\text {Kipl }}$ & 5'-GGAATAAGGAAGCGACCTG & 5'-CCGTCTGAAACATTTTCTTC \\
Caspase 3 & 5'-GGCGTGTCATAAAATACCAG & 5'-ACAAAGCGACTGGATGAA \\
MMP9 & 5'-AACTACGACCGGGACAAG & 5'-ATTCACGTCGTCCTTATGC \\
GAPDH & 5'-GGCTGCTTTTAACTCTGGTA & 5'-AGCAAGGACAGAAACTCAGA \\
Psoriasin (ribozyme) & 5'-CTGCAGTCACAGGCACTAAGGAA & 5'-ACTAGTGGCTGGTGTTTGACATTTCGTCCTCA \\
& GTTGGGCTGATGAGTCCGTGAGGA & CGGACT \\
\hline
\end{tabular}

from all patients involved. Total RNA extraction was then performed using TRI reagent (Sigma-Aldrich). Psoriasin transcripts were determined using QPCR together with an internal control keratin 19 (CK19). Normalised Psoriasin transcript levels are shown in Table II. Primer sequences are provided in Table I.

In vitro cell growth assay. A standard growth assay was undertaken as previously described $(15,24)$. Cells were plated into a 96-well plate (3,000 cells/well) and growth was assessed after 1, 3 and 5 days. Crystal violet was used to stain the cells, and absorbance was determined at a wavelength of $540 \mathrm{~nm}$ using a spectrophotometer (Elx800; Bio-Tek, Bedfordshire, UK).

Electric cell-substrate impedance sensing (ECIS) based cellular migration assays. An ECIS-Ztheta instrument (Applied Biophysics Ltd.; Troy, NJ, USA) was used with a 96-well 96W1E microarrays and wounding module. Pancreatic cancer cells were seeded at 40,000 cells per well and cell adhesion was tracked immediately over a range of frequencies from 1,000 to $64,000 \mathrm{~Hz}$. Once the cells reached confluence, a current of 2,600 $\mu \mathrm{A}$ was passed across each well for $20 \mathrm{sec}$ to produce a reproducible wound, after which cell migration was automatically tracked.

Cell-matrix adhesion assay. A total of 20,000 cells were added to each well of a 96-well plate previously prepared by coating with Matrigel ( $5 \mu \mathrm{g} /$ well). The cells were incubated at $37^{\circ} \mathrm{C}$ in $5 \% \mathrm{CO}_{2}$ for $45 \mathrm{~min}$ and the medium was then discarded. Non-adherent cells were washed off using balanced salt solution (BSS) buffer. Adherent cells were then fixed in $4 \%$ formalin, stained with crystal violet and absorbance determined at $540 \mathrm{~nm}$.

Cell-cell adhesion assay. LP-9 mesothelial cells were trypsinised and transferred to a 96-well plate at 30,000 cells per well and grown to confluence over a 24-h period.
Table II. Psoriasin transcript levels in pancreatic cancer.

\begin{tabular}{|c|c|c|c|}
\hline & $\mathrm{N}$ & $\begin{array}{c}\text { Mean } \pm \text { SEM } \\
\text { (copies/25 ngRNA) }\end{array}$ & $\mathrm{p}$-value \\
\hline \multicolumn{4}{|l|}{ Clinical samples } \\
\hline Tumour & 126 & $162.9 \pm 75.8$ & 0.32 \\
\hline Normal & 114 & $1,7793 \pm 17,660$ & \\
\hline \multicolumn{4}{|l|}{ Histology } \\
\hline Adeno & 108 & $134.7 \pm 79$ & \\
\hline Ductal & 4 & $981 \pm 981$ & $0.45 \mathrm{vs}$ adeno \\
\hline Others & 14 & $147 \pm 147$ & 0.94 vs adeno \\
\hline \multicolumn{4}{|l|}{ T staging } \\
\hline 1 & 2 & $1.77 \pm 1.77$ & \\
\hline 2 & 19 & $0.847 \pm 0.799$ & \\
\hline 3 & 73 & $184.5 \pm 97.6$ & 0.064 vs T2 \\
\hline 4 & 10 & $644 \pm 640$ & \\
\hline $\mathrm{T} 1-2$ & 21 & & \\
\hline T3-4 & 83 & $240 \pm 114$ & 0.04 \\
\hline \multicolumn{4}{|l|}{ Node status } \\
\hline Node-negative & 46 & $272 \pm 166$ & \\
\hline Node-positive & 4 & $1.77 \pm 1.77$ & 0.11 \\
\hline \multicolumn{4}{|l|}{ Metastasis } \\
\hline Yes & 9 & $0.00014 \pm 0.00010$ & \\
\hline No & 117 & $175.5 \pm 81.5$ & 0.033 \\
\hline \multicolumn{4}{|l|}{ Clinical outcome } \\
\hline Died & 89 & $90.1 \pm 64.3$ & \\
\hline Alive & 26 & $402 \pm 283$ & 0.29 \\
\hline \multicolumn{4}{|l|}{ Embolism } \\
\hline Yes & 35 & $212 \pm 162$ & \\
\hline No & 73 & $179 \pm 105$ & 0.87 \\
\hline
\end{tabular}


Pancreatic cancer cells were stained with $10 \mu \mathrm{g} / \mathrm{ml}$ DiI membrane stain (1,1'-dioctadecyl-3,3,3',3'-tetramethylindocarbocyanine perchlorate, Life Technologies) before being added at 20,000 cells per well to the mesothelial cell monolayer. Pancreatic cancer cells were left to adhere for $40 \mathrm{~min}$ before non-adherent cells were washed off using BSS buffer. Adherent cells were then fixed (4\% formalin) and images were taken at 549 excitation/565 emission and phase contrast using an EVOS FL auto (Life Technologies), before the total number of adherent pancreatic cancer cells was counted.

In vitro invasion assay. Transwell inserts with $8 \mu \mathrm{m}$ pore size (Greiner Bio-One, Gloucester, UK) were coated with $50 \mu \mathrm{g}$ Matrigel and air-dried before being rehydrated. A total of 20,000 cells were added to each insert. Following 72 -h incubation, cells that had migrated through the matrix and pores were fixed ( $4 \%$ formalin), stained in crystal violet and absorbance determined at $540 \mathrm{~nm}$.

Gelatin zymography assay. Pancreatic cancer cells $\left(3 \times 10^{6}\right)$ were seeded into a $75-\mathrm{cm}^{2}$ flask. Following overnight culture, cells were washed twice with serum-free DMEM and cultured in serum-free DMEM for $6 \mathrm{~h}$. The conditioned medium was then collected by centrifugation to remove any cells. Samples were prepared in non-reducing sample buffer (containing $0.625 \mathrm{mM}$ Tris- $\mathrm{HCl}, 10 \%$ glycerol, $2 \%$ SDS, and $2 \%$ bromophenol blue). Each sample (30 $\mu$ l) was loaded into each lane and separated by $10 \%$ sodium dodecyl sulfate polyacrylamide gel electrophoresis (SDS-PAGE) on gels containing $1 \mathrm{mg} / \mathrm{ml}$ gelatine (Sigma-Aldrich). The gel was then renatured at room temperature in washing buffer (containing 2.5\% Triton X-100 and $0.02 \% \mathrm{NaN}_{3}$ ), before being incubated in a buffer containing $50 \mathrm{mM}$ Tris- $\mathrm{HCl}\left(\mathrm{pH}\right.$ 7.6), $5 \mathrm{mM} \mathrm{CaCl}_{2}$, and $0.02 \% \mathrm{NaN}_{3}$ for $72 \mathrm{~h}$ before staining with Coomassie blue. The clear bands of gelatin digested by MMPs was documented and analysed using densitometry.

Cell aggregation assay. Cell aggregation was measured over a time course of $3 \mathrm{~h}$, at $1 \mathrm{~h}$ intervals. MiaPa-Ca-1 cells with varying Psoriasin expression were harvested using trypsin. A small amount was aliquoted for initial measurements. The remaining solution was left at $37^{\circ} \mathrm{C}$, on a tilt table, to prevent adherence. The collected samples were kept on ice to prevent additional aggregation. Cells were aliquoted out at 1 , 2 and 3 h. Cell aggregation was measured using a Neubauer haemocytometer (Celeromics, Cambridge, UK) under a light microscope, with total individual cells counted followed by the number of cell groups.

Anoikis assay. Cells $(250,000-500,000)$ per experiment were transferred to a fresh UC and spun down in a centrifuge at $1700 \mathrm{rpm}$ for $5 \mathrm{~min}$ and washed with ice-cold PBS and re-centrifuged. The cells were suspended in $250 \mu \mathrm{l}$ of Annexin $\mathrm{V}$ binding (Invitrogen) buffer per 250,000 cells. This solution $(100 \mu \mathrm{l})$ was mixed with $5 \mu \mathrm{l}$ of pre-mixed staining solution ( $0.2 \mu \mathrm{l}$ propidium iodide, $0.8 \mu \mathrm{l}$ Annexin V-FITC, $4 \mu \mathrm{l}$ Annexin $\mathrm{V}$ binding buffer) (Invitrogen) and left in the dark, at room temperature, for $30 \mathrm{~min}$. It was then diluted with $400 \mu \mathrm{l}$ of filtered PBS and kept on ice. The remaining cell solution was incubated at $37^{\circ} \mathrm{C}$ at $5 \% \mathrm{CO}_{2}$ and the process repeated at
1 and $2 \mathrm{~h}$. The samples were then run through a flow cytometer (Cyflow, Sysmex UK Ltd.).

Western blot analysis. Equal amount of total proteins of each cell line was separated on an SDS-PAGE gel. The proteins were then electrically transferred on to a nitrocellulose membrane and probed with anti-caspase 3 and GAPDH antibodies (Santa Cruz Biotechnology, CA, USA), respectively, and also corresponding peroxidase conjugated secondary antibodies (Sigma-Aldrich). Images of the protein bands were developed using a chemiluminescence detection kit (Luminata, Millipore) and a UVITech imager (UVITech, Inc.).

Statistical analysis. Statistical analysis was performed using SPSS18 (SPSS Inc., Chicago, IL, USA). The t-test and Mann-Whitney U test were used for normally distributed and non-normally distributed data respectively. Kaplan-Meier analysis was used to analyse the correlation with patient survival. Differences were considered statistically significant at $\mathrm{p}<0.05$.

\section{Results}

Expression of Psoriasin in pancreatic cancer, and evaluation of Psoriasin levels in cell lines. In the search of gene expression array data base at PubMed, a reduction was seen in the expression of Psoriasin in pancreatic cancers in comparison with the paired adjacent normal pancreatic tissues (GDS4336) (Fig. 1A). We further determined the transcript levels of Psoriasin in a cohort of 126 pancreatic tumours and 114 adjacent normal pancreatic tissues. Psoriasin expression appeared to be reduced in the tumours but did not reach a significant level in comparison with the adjacent normal tissues (Table II). An even lower expression of Psoriasin was seen in tumours with distant metastases. Interestingly, higher Psoriasin transcript levels were seen in locally invasive tumours which extended beyond the pancreas (T3 and T4) in comparison with tumours confined to the pancreas (T1 and T2) (Table II). It suggests that Psoriasin plays a significant role in regulation of invasion of pancreatic cancer cells. To clarify the involvement of Psoriasin in metastasis, we analysed the expression of Psoriasin in another gene expression array of pancreatic tumours which includes 145 primary tumours and 61 metastatic tumours (GSE71729) (25). An increased expression of Psoriasin was seen in the secondary tumours in comparison with its expression in primary tumours (Fig. 1B).

The mRNA expression of Psoriasin in three different pancreatic cancer cell lines was evaluated using RT-PCR (Fig. 1C). RAGE, the receptor of Psoriasin was detected in the three pancreatic cancer cell lines. PCR products of $528 \mathrm{bp}$ were amplicons of both variant 2 and 4 , while 480 -bp products represented amplicons from variant $1,3,5,6,7,8$ and 9 . However, exact variants expressed in these cell lines are yet to be further determined (Fig. 1C). The expression of Psoriasin in MIA-PaCa-2 is higher than that for PANC-1, and lowest in AsPc-1. Psoriasin knockdown and overexpression was verified in the MIA-PaCa-2 and PANC-1 cell lines transfected with ribozyme transgenes using RT-PCR (Fig. 1D) and qPCR (Fig. 1E). The Psoriasin-modified MIA-PaCa-2 and PANC-1 cell lines were used for subsequent experiments. 
A

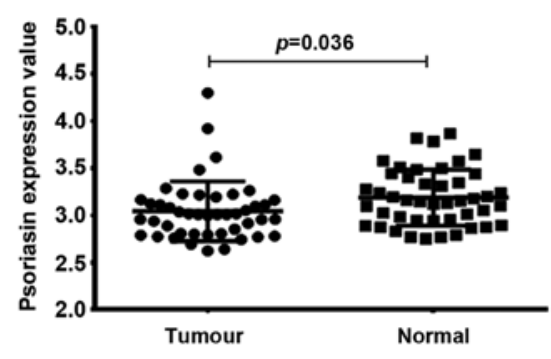

C

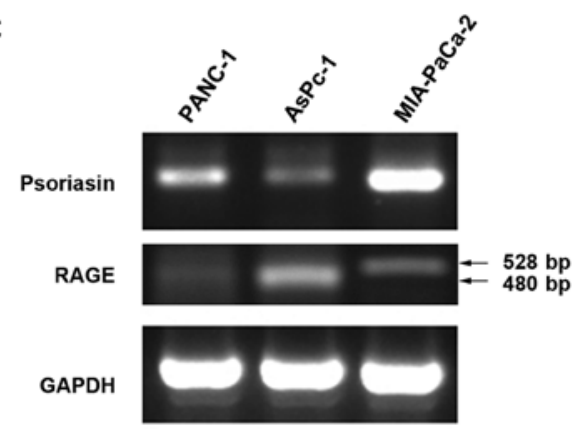

B

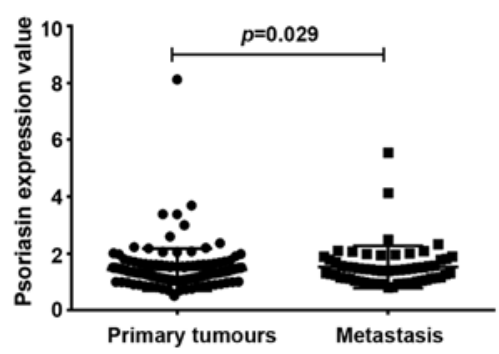

D
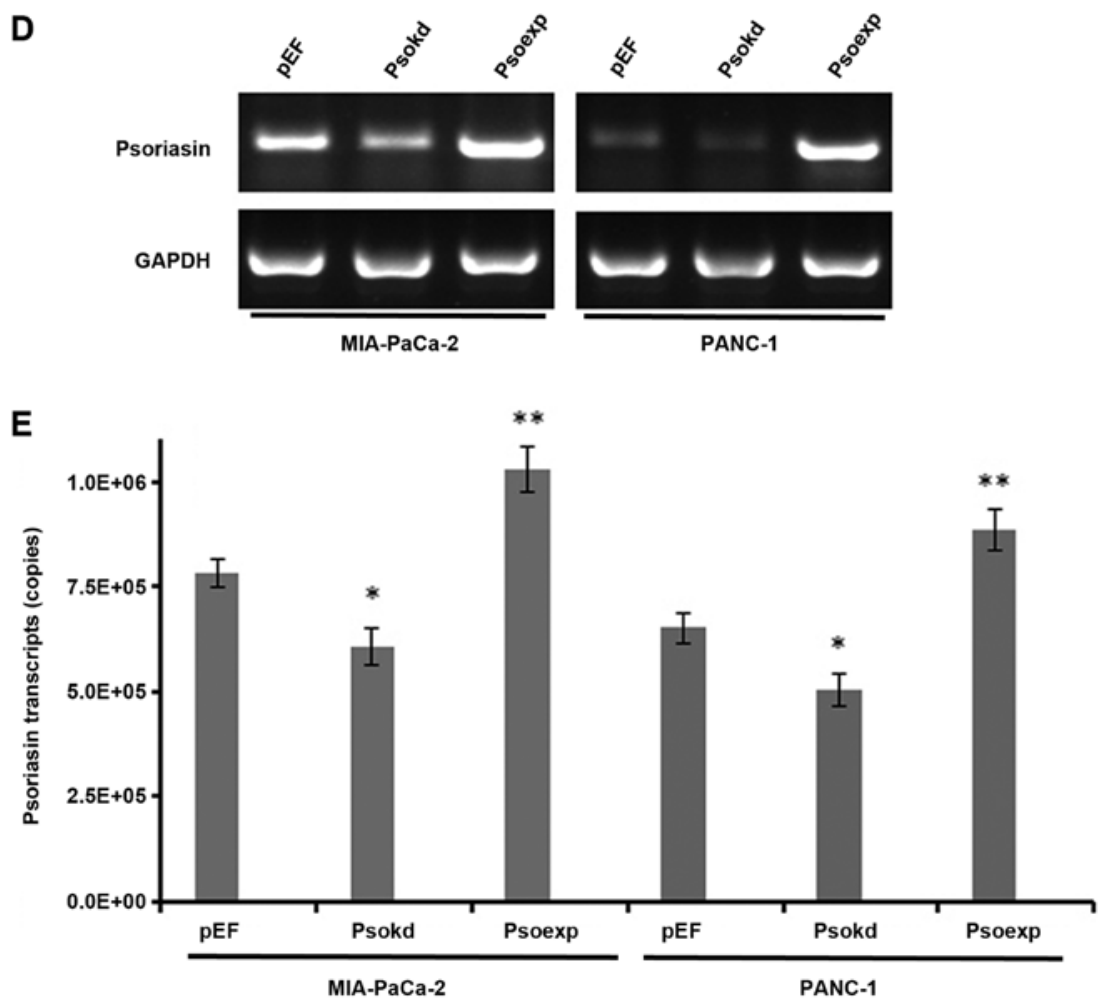

Figure 1. Expression of Psoriasin in pancreatic cancer and pancreatic cancer cell lines with altered Psoriasin expression. (A) Reduced expression of Psoriasin was seen in a cohort of 45 pancreatic ductal adenocarcinomas in comparison with its expression in the paired adjacent normal pancreatic tissues (GDS4336) (26). (B) An elevated expression of Psoriasin was seen in metastases of pancreatic cancer compared with its expression in primary tumours (GSE71729) (25). (C) Psoriasin and RAGE transcripts were detected in PANC-1, AsPC-1 and MIA-PaCa-2 cell lines using conventional PCR. Knockdown and overexpression of Psoriasin were performed using anti-Psoriasin ribozyme transgenes and a recombinant plasmid vector carrying full-length human Psoriasin coding sequence, respectively. The altered expression of Psoriasin in the transfected pancreatic cancer cell lines (MIA-PaCa-2 and PANC-1) was verified using conventional PCR (D) and real-time PCR (E). ${ }^{*} \mathrm{p}<0.05,{ }^{* *} \mathrm{p}<0.01$.

Effect of Psoriasin knockdown and overexpression on pancreatic cancer cell growth and migration. A significant decrease in cellular growth was observed in Psoriasin knockdown MIA-PaCa-2 (Fig. 2A, p<0.001) and PANC-1 (Fig. 2B, p <0.05) cell lines in comparison with controls. Conversely, overexpres- sion of Psoriasin resulted in increased growth of MIA-PaCa-2 and PANC-1 cell lines ( $\mathrm{p}<0.05)$.

Psoriasin knockdown resulted in decreased migration of MIA-PaCa-2 (Fig. 2C, p<0.001) and PANC-1 (Fig. 2D, p<0.05) cell lines compared to controls. Conversely, Psoriasin over- 
A

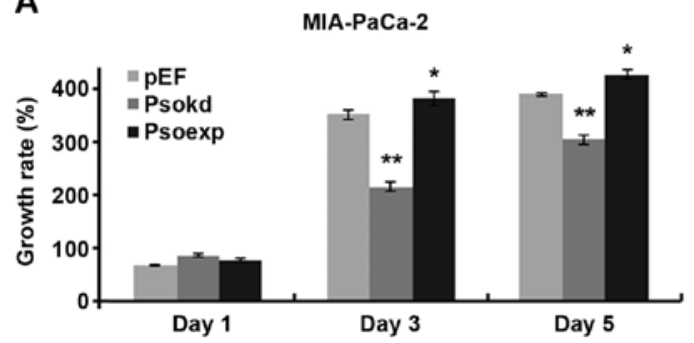

C

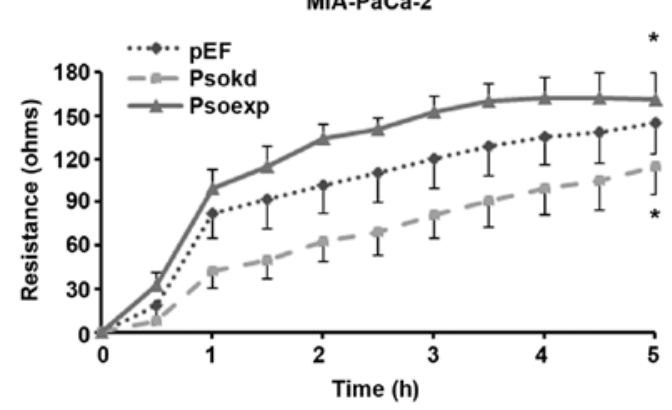

B

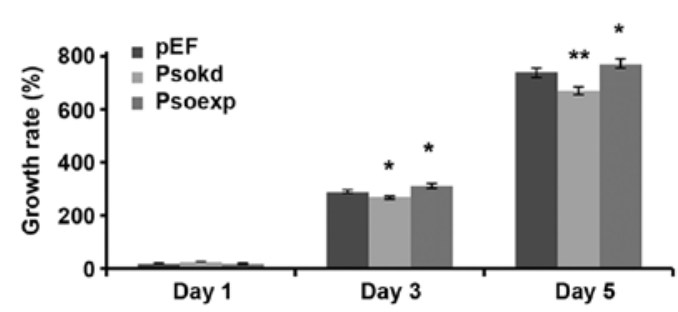

D

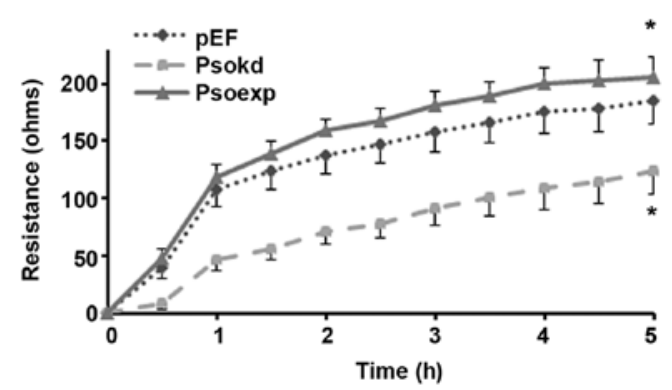

Figure 2. Effect of Psoriasin on proliferation and migration of pancreatic cancer cell lines. The influence on cell proliferation was determined over a period up to five days. Impact on in vitro proliferation was determined for MIA-PaCa-2 (A) and PANC-1 (B) cell lines a colorimetric method. The migration of pancreatic cancer cell lines were measured using ECIS for MIA-PaCa-2 (C) and for PANC-1 (D). Six repeats were included for each cell line and three independent experiments were performed. Growth rate was calculated against the corresponding day 0 control. ${ }^{*} \mathrm{p}<0.05,{ }^{* *} \mathrm{p}<0.01$.
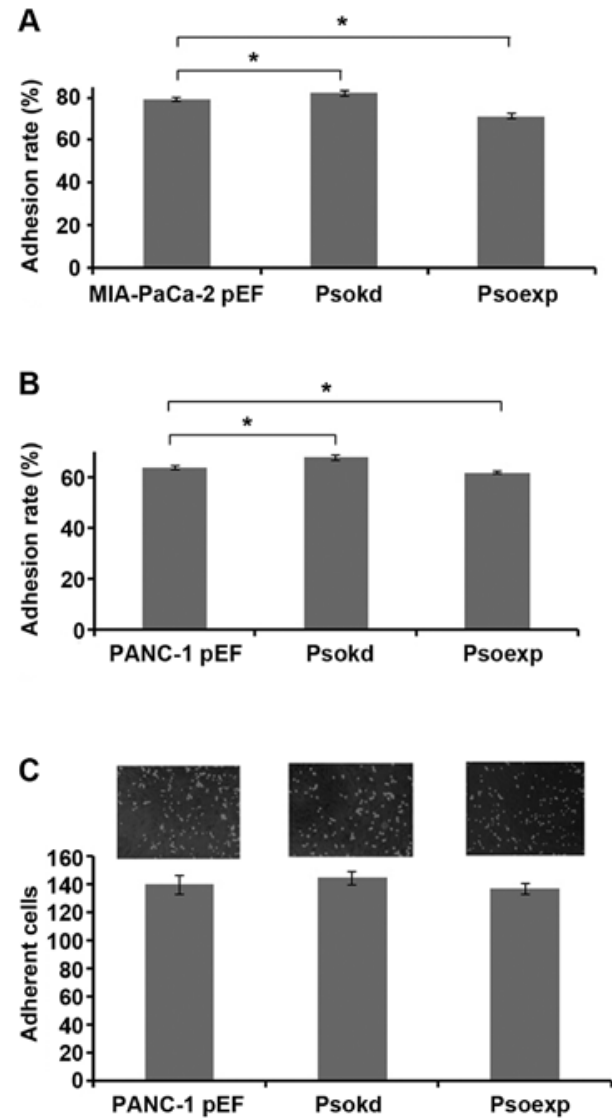

Figure 3. Influence on adhesion of pancreatic cancer cell lines. (A) Adhesion of MIA-PaCa-2 cells was altered by the knockdown and overexpression of Psoriasin. (B) Impact on cell adhesion of PANC-1 cell by the differential expression of Psoriasin. (C) Adhesion of PANC-1 cells to the peritoneal mesothelial cells. Adhesion rate was calculated based on the number of cells seeded. Six repeats were included for each cell line and three independent experiments were performed. ${ }^{*} \mathrm{p}<0.05$. expression resulted in increased migration of MIA-PaCa-2 $(\mathrm{p}<0.001)$ and PANC-1 $(\mathrm{p}<0.05)$ cell lines.

Influence of Psoriasin expression on pancreatic cancer cell adhesion. An in vitro cell-matrix adhesion assay was adopted to investigate the effect of Psoriasin knockdown and overexpression on the adhesive ability of pancreatic cancer cells to extracellular matrix. MIA-PaCa-2 (Fig. 3A, p<0.05) and PANC-1 (Fig. 3B, p<0.05) Psoriasin overexpressing cells exhibited decreased cell-matrix adhesion whilst Psoriasin knockdown resulted in increased adhesion to matrix $(\mathrm{p}<0.05)$.

According to the involvement in adhesion of pancreatic cancer cells, we were curious about a possible implication in dissemination through peritoneal cavity. Therefore, we determined the effect of Psoriasin expression on pancreatic cancer cell adhesion to mesothelial which constitute peritoneum. Neither Psoriasin overexpression nor knockdown had any significant effect on the adhesion of PANC-1 cells to peritoneal mesothelia compared to control (Fig. 3C).

Effect of Psoriasin expression on pancreatic cancer cell invasion. The influence of Psoriasin expression on MIA-PaCa-2 and PANC-1 cell invasion was examined. Interestingly, Psoriasin overexpression resulted in increased invasion of MIA-PaCa-2 (Fig. 4A, p<0.001) and PANC-1 (Fig. 4B, $\mathrm{p}<0.05)$ cell lines whilst Psoriasin knockdown resulted in decreased invasion of MIA-PaCa-2 (p<0.001) and PANC-1 $(\mathrm{p}<0.05)$ cells.

At the mRNA level, MMP-9 expression was significantly increased in Psoriasin overexpression MIA-PaCa-2 cells compared to controls (Fig. 4C). Conversely, MMP-9 expression was decreased in Psoriasin knockdown MIA-PaCa-2 cells. As the results from zymography show, MMP-2 and 
A

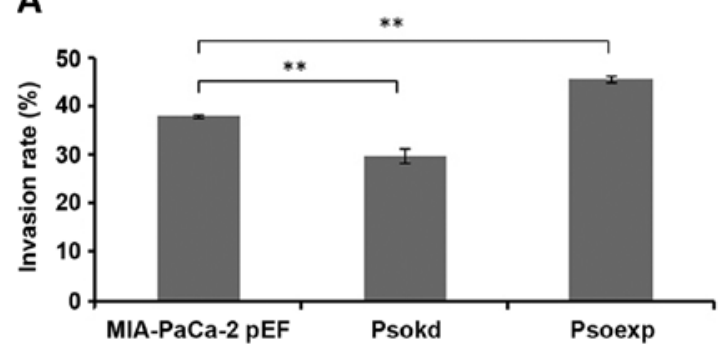

C

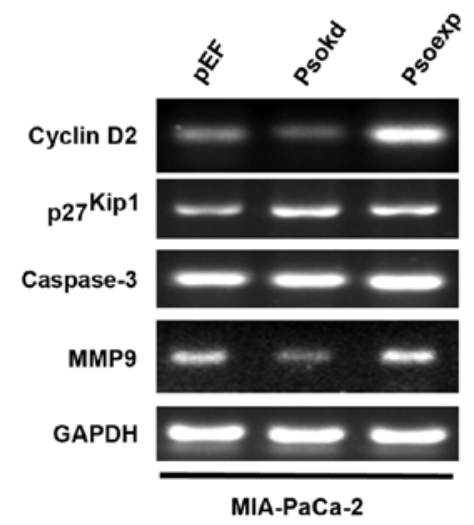

B

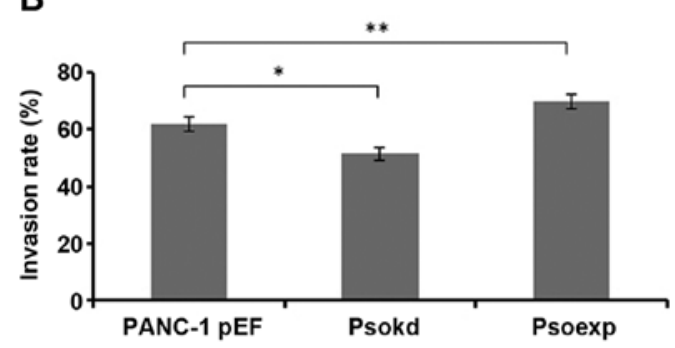

D

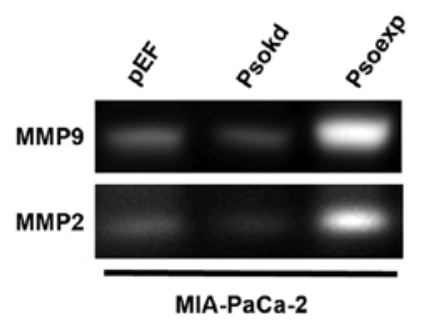

Figure 4. Psoriasin and invasion of pancreatic cancer cell lines. The invasion of MIA-PaCa-2 (A) and PANC-1 (B) cell lines were determined using a Transwell invasion assay in triplicates. (C) Expression of MMP-2, p27 ${ }^{\mathrm{Kip} 1}$, cyclin D2 and caspase-3 was detected in MIA-PaCa-2 cells with differential expression of Psoriasin using conventional PCR. (D) Active MMP-2 and MMP-9 were determined using gelatine zymography. Invasion rates were calculated against corresponding control in which the same number of cells were seeded at beginning of the experiments. Three independent experiments were performed. ${ }^{*} \mathrm{p}<0.05,{ }^{* *} \mathrm{p}<0.01$.

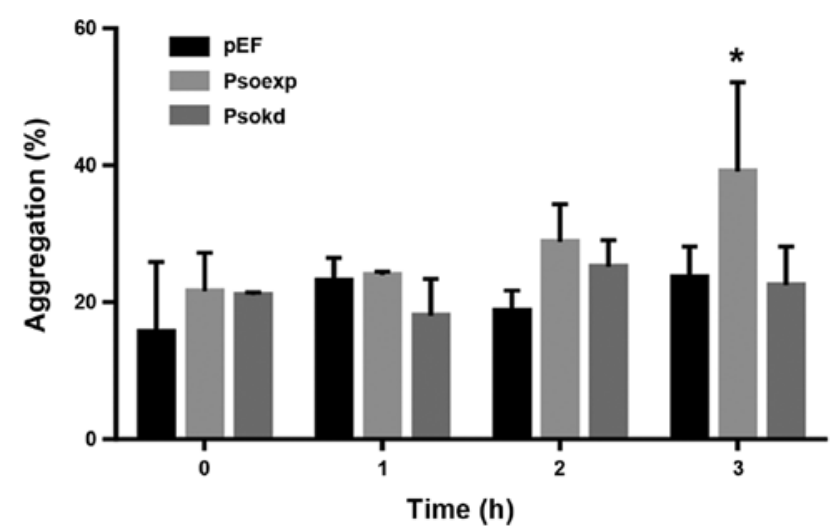

Figure 5. Psoriasin and aggregation of pancreatic cancer cells. Aggregation of MIA-PaCa-2 cells was determined over a duration $\leq 3 \mathrm{~h}$. Three independent experiments were performed. ${ }^{*} \mathrm{p}<0.05$.

MMP-9 activity is increased in Psoriasin overexpression MIA-PaCa-2 cells compared to control (Fig. 4D), whilst MMP-2 and MMP-9 activity is decreased in Psoriasin knockdown MIA-PaCa-2 cells. As shown in Fig. 4C, decreased Psoriasin expression resulted in the decreased expression of cyclin D2 at the mRNA level in MIA-PaCa-2 cells in which an increased level of $\mathrm{p} 27^{\mathrm{Kipl}}$ was also noted. Moreover, overexpression of Psoriasin resulted in increased cyclin D2 expression.

Influence of Psoriasin on aggregation and survival of pancreatic cancer cells. In order to evaluate how MIA-PaCa-2 cells interact with one another in suspension, a cell aggregation assay was performed. Cells with increased Psoriasin expression demonstrated an increased propensity to form cell-cell contacts whilst in suspension, reaching significance at $3 \mathrm{~h}$ (Fig. 5, p<0.05). To determine whether this observation had an impact on the anoikis resistance in this cell line, an apoptosis assay was performed. We observed cell survival after suspension was increased in Psoriasin overexpressing cell lines (Fig. 6). Western blot analyses of adherent cells showed an enhanced activation of caspase-3 in MIA-PaCa-2 cells as cleaved proteins in comparison with the control (Fig. 7). A reduction in the cleavage of caspase-3 was not observed in the Psoriasin overexpression cells compared with the control which also exhibited a lower level of the activation.

\section{Discussion}

Psoriasin was first identified as being overexpressed in the hyperproliferative skin disease psoriasis. Numerous studies have since demonstrated Psoriasin overexpression to be associated with tumour progression. Upregulation of Psoriasin in cancer was initially identified in pre-invasive carcinomas; whether this upregulation occurs in pancreatic intra-epithelial neoplasia progression that proceeds to pancreatic adenocarcinoma remains to be elucidated. Increased Psoriasin expression has also been identified in cancers at an advanced stage. In breast cancer, Psoriasin overexpression is associated with metastasis and poor prognosis. In the present study, Psoriasin expression was determined in a cohort of pancreatic cancer patients. Psoriasin expression tended to be reduced in the 

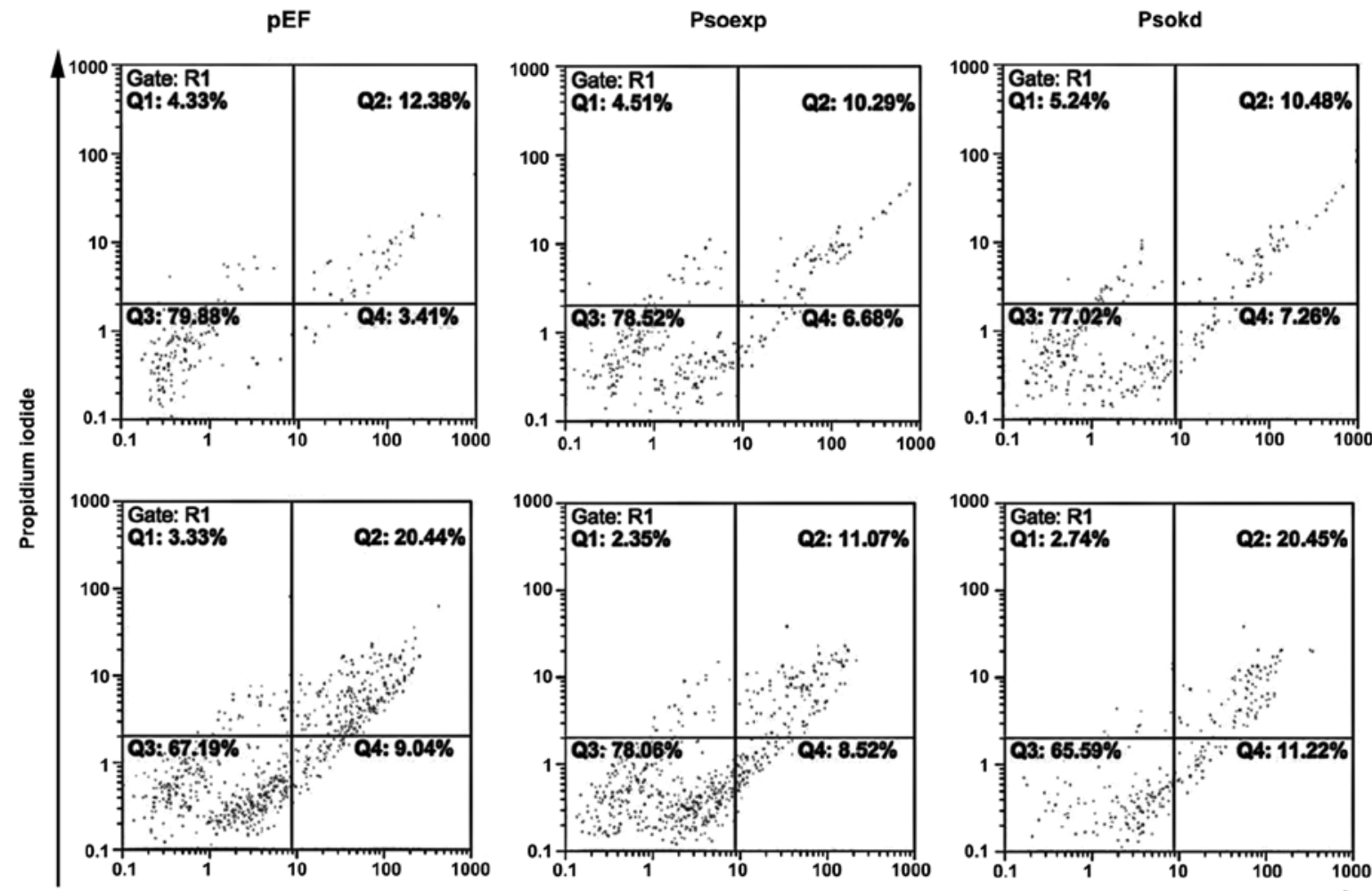

$0 \mathrm{~h}$
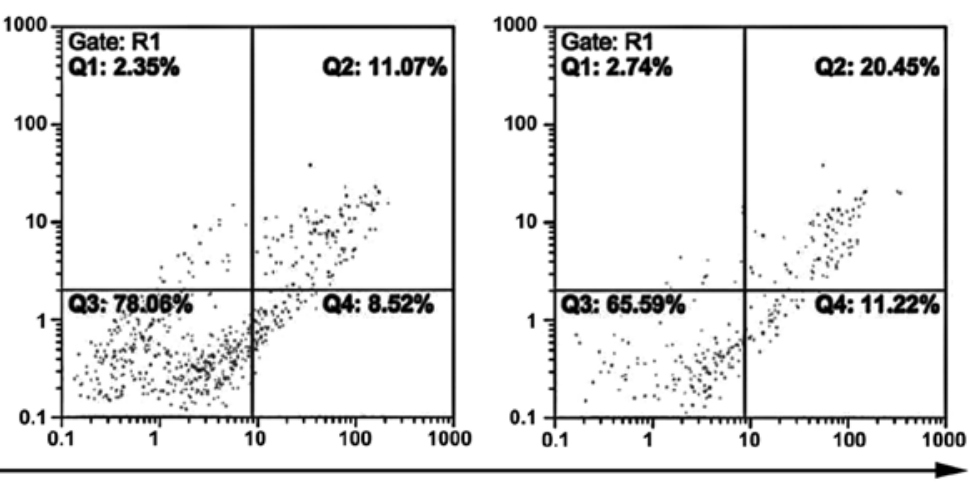

$1 \mathrm{~h}$

Figure 6. Psoriasin and anoikis of pancreatic cancer cells. Apoptosis of suspension MIA-PaCa-2 cells with altered expression of Psoriasin was determined using a flow cytometric method.

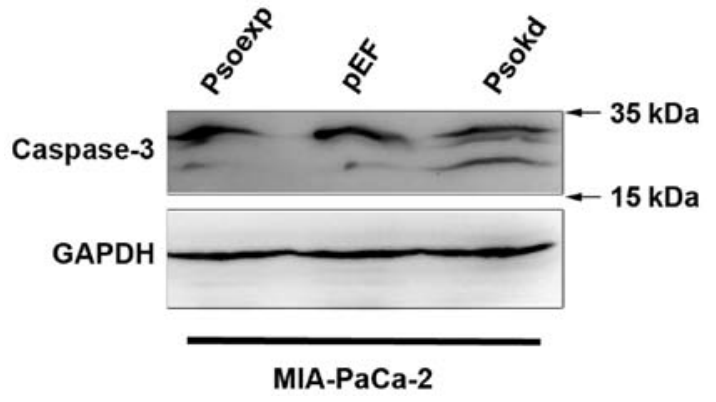

Figure 7. Caspase 3 in MIA-PaCa-2 cells were detected using western blot analysis.

pancreatic cancers compared to adjacent normal pancreatic tissues, though did not reach statistical significance. This observation is similar to findings from a GEO data set (GDS4336) (Fig. 1A) (26). A reduced expression was noted in primary tumours ( $\mathrm{n}=9)$ with distant metastases. This finding is yet to be verified by examining of a large cohort pancreatic primary tumours with a reasonable number of primary tumours which have distant metastasis. In an analysis of a gene expression array data, an increased expression levels of Psoriasin was seen in metastases of pancreatic cancer in comparison with primary tumours (Fig. 1B). Interestingly, a greater expression of Psoriasin was evident in locally advanced pancreatic tumours. It suggests that Psoriasin may play differential roles during the development and progression of the disease, in particular, the metastatic process.
We determined the expression of Psoriasin in the cell lines AsPc-1, MIA-PaCa-2 and PANC-1, and expression appeared highest in MIA-PaCa-2 which is the most tumourigenic of the three cell lines (27). These results demonstrate that Psoriasin overexpression is associated with increased cancer cell growth in vitro, whilst knockdown inhibits growth. Interestingly, during breast cancer progression, Psoriasin has been shown to interact with Jab1 (c-jun activation-domain binding protein), which is involved in proteosomal degradation and signal transduction. Interaction between Psoriasin and Jab1 results in increased activator protein-1 (AP-1) activity, increased expression of AP-1 and HIF-1-dependent genes, and reduced expression of the cell cycle inhibitor $\mathrm{p} 27^{\mathrm{Kipl}}$, resulting in enhanced tumourigenesis and metastasis in vivo (28). It may be that in pancreatic cancer, the same mechanisms are taking place promoting tumour growth and metastasis. Jab1 is a negative regulator of p2 $7^{\text {Kipl }}$, promoting its degradation (29). p2 $7^{\text {Kipl }}$ normally binds to and prevents the activation of cyclin complexes controlling cell cycle progression at G1 (30). Thus, it may be that increased interaction between Psoriasin and Jab1 results in decreased p2 $7^{\text {Kipl }}$. In line with this, an increased expression of p27 ${ }^{\text {Kipl }}$ was also observed in the Psoriasin knockdown cells (Fig. 4C). We also found that Psoriasin overexpression results in increased expression of cyclin D2, which may explain the mode of action for Psoriasin-mediated promotion of cyclin activation and cell cycle progression. Additionally, differential expression of RAGE, the receptor of Psoriasin was seen in three pancreatic cancer cell lines. RAGE has 8 isoforms of protein products encoded by 9 different splicing variants in humans (listed at PubMed Gene). However, we cannot identify which vari- 
ants were expressed by these cell lines. The exact role played by RAGE in mediating functions of Psoriasin in pancreatic cancer is yet to be investigated.

In this study, Psoriasin expression was inversely linked to cell-matrix adhesion. This is similar to our results observed in both prostate and lung cancer $(11,15)$. It suggests that expression of Psoriasin is a response by cancer cells to changes of cell-matrix adhesion and reciprocally affects cell adhesion to matrix. We also found Psoriasin expression has no effect on the adhesion of pancreatic cancer cells to peritoneal mesothelial in vitro, and conclude that Psoriasin may not be required for the adhesion during peritoneal metastasis of pancreatic cancer.

Psoriasin is regarded as an inflammation-associated protein and has chemoattractant properties, promoting migration of granulocytes, lymphocytes, macrophages and monocytes. Our study showed Psoriasin overexpression results in increased migration of pancreatic cancer cells. The multiligand receptor for advanced glycation end-products (RAGE) has been identified as a Psoriasin receptor, and implicated in leukocyte migration and the inflammatory process. It may be that, similar to leukocyte migration, Psoriasin attaches to RAGE in order to promote cancer cell migration (5).

Further to its influences on cell growth, adhesion and migration, we also examined the effect of Psoriasin on pancreatic cancer cell invasion. It is well known that activation of MMP-2 and MMP-9 promotes the invasive and metastatic potential of pancreatic cancer cells $(31,32)$. In our recent study of Psoriasin in prostate cancer, Psoriasin has been shown to have an effect on prostate cancer cell invasion via MMPs (11). This is subsequently confirmed herein, whereby Psoriasin overexpression in pancreatic cancer cells resulted in increased MMP-2 and MMP-9 expression and activity. Taken together, these data suggest Psoriasin regulates invasion of pancreatic cancer cells via regulation of MMPs. In a recent study, Morgan et al observed interaction between Psoriasin and the cytoplasmic domain of the integrin $\beta 6$ subunit is required for $\alpha v \beta 6$-dependent breast cancer cell invasion. Similarly, they showed upregulation of MMPs in Psoriasin overexpressing breast cancer cells (33). In line with its higher expression levels in local invasive tumours, Psoriasin promotes invasion of pancreatic cancer cells which leads to a greater local invasive expansion of the disease.

A recent report of disruption of cell anchorage inducing apoptosis led us to investigate whether Psoriasin has a role of inducing this form of anoikis resistance in pancreatic cancer cells (34). Anoikis is referred to as a programmed cell death or apoptosis which happens to adherent cells lacking anchorage (34). It can occur during the dissemination of pancreatic cancer cells through circulation and peritoneal cavity when they lose anchorage. At $3 \mathrm{~h}$ we saw a significant rise of cell-cell aggregates, indicating a role for Psoriasin in inducing these aggregates. Previous experiments showed a role for Psoriasin in preventing anoikis (34), a result we confirmed in our cell lines, hinting that cell-cell aggregation may contribute to preventing anoikis. Despite this, based on our results, the number of cell-cell aggregates show a significant increase only at $3 \mathrm{~h}$, whereas cells display anoikis resistance at $1 \mathrm{~h}$, indicating other mechanisms must be at play to compensate for the disparity. Western blot analyses of adherent cells showed an increased activation of caspase 3 in the Psoriasin knockdown MIA-PaCa-2 cells. The involvement of intrinsic and extrinsic caspase pathways and activation of caspase- 3 in pancreatic cancer cells undergoing anoikis remains unclear and is yet to be investigated. Further investigation is also required to reveal molecules involved in the enhanced cell-cell adhesion and aggregation.

In conclusion, reduced expression of Psoriasin was seen in pancreatic cancers with distant metastases, whilst higher transcript levels were seen in locally advanced tumours. Psoriasin expression in pancreatic cancer cells is associated with cell growth, cell-matrix adhesion and migration. Psoriasin regulates invasion of pancreatic cancer cells via expression of MMPs. The implication of Psoriasin expression in invasion, disease progression and potential as a therapeutic target warrants further investigation.

\section{Acknowledgements}

The authors thank the support from Cancer Research Wales, Life Sciences Research Network Wales (Welsh Government's Ser Cymru Program) and Albert Huang Foundation. Ying Liu, Yanan Gu and Gang Chen are recipients of China Medical Scholarship from the Cardiff University.

\section{References}

1. Madsen P, Rasmussen HH, Leffers H, Honoré B, Dejgaard K, Olsen E, Kiil J, Walbum E, Andersen AH, Basse B, et al: Molecular cloning, occurrence, and expression of a novel partially secreted protein "psoriasin" that is highly up-regulated in psoriatic skin. J Invest Dermatol 97: 701-712, 1991.

2. Hoffmann HJ, Olsen E, Etzerodt M, Madsen P, Thøgersen HC, Kruse T and Celis JE: Psoriasin binds calcium and is upregulated by calcium to levels that resemble those observed in normal skin. J Invest Dermatol 103: 370-375, 1994.

3. Børglum AD, Flint T, Madsen P, Celis JE and Kruse TA: Refined mapping of the psoriasin gene S100A7 to chromosome 1cen-q21. Hum Genet 96: 592-596, 1995.

4. Schäfer BW and Heizmann CW: The S100 family of EF-hand calcium-binding proteins: Functions and pathology. Trends Biochem Sci 21: 134-140, 1996.

5. Wolf R, Howard OM, Dong H-F, Voscopoulos C, Boeshans K, Winston J, Divi R, Gunsior M, Goldsmith P, Ahvazi B, et al: Chemotactic activity of S100A7 (Psoriasin) is mediated by the receptor for advanced glycation end products and potentiates inflammation with highly homologous but functionally distinct S100A15. J Immunol 181: 1499-1506, 2008.

6. Boniface K, Bernard FX, Garcia M, Gurney AL, Lecron JC and Morel F: IL-22 inhibits epidermal differentiation and induces proinflammatory gene expression and migration of human keratinocytes. J Immunol 174: 3695-3702, 2005

7. Boniface K, Diveu C, Morel F, Pedretti N, Froger J, Ravon E, Garcia M, Venereau E, Preisser L, Guignouard E, et al: Oncostatin $\mathrm{M}$ secreted by skin infiltrating T lymphocytes is a potent keratinocyte activator involved in skin inflammation. J Immunol 178: 4615-4622, 2007.

8. Gläser R, Harder J, Lange H, Bartels J, Christophers E and Schröder JM: Antimicrobial psoriasin (S100A7) protects human skin from Escherichia coli infection. Nat Immunol 6: 57-64, 2005.

9. Jinquan T, Vorum H, Larsen CG, Madsen P, Rasmussen HH, Gesser B, Etzerodt M, Honoré B, Celis JE and ThestrupPedersen K: Psoriasin: A novel chemotactic protein. J Invest Dermatol 107: 5-10, 1996.

10. Jiang WG, Watkins G, Douglas-Jones A and Mansel RE: Psoriasin is aberrantly expressed in human breast cancer and is related to clinical outcomes. Int J Oncol 25: 81-85, 2004.

11. Ye L, Sun PH, Martin TA, Sanders AJ, Mason MD and Jiang WG: Psoriasin (S100A7) is a positive regulator of survival and invasion of prostate cancer cells. Urol Oncol 31: 1576-1583, 2013. 
12. Moubayed N, Weichenthal M, Harder J, Wandel E, Sticherling M and Gläser R: Psoriasin (S100A7) is significantly up-regulated in human epithelial skin tumours. J Cancer Res Clin Oncol 133: 253-261, 2007.

13. Tripathi SC, Matta A, Kaur J, Grigull J, Chauhan SS, Thakar A, Shukla NK, Duggal R, DattaGupta S, Ralhan R, et al: Nuclear S100A7 is associated with poor prognosis in head and neck cancer. PLoS One 5: e11939, 2010.

14. Celis JE, Rasmussen HH, Vorum H, Madsen $\mathrm{P}$, Honoré B, Wolf $\mathrm{H}$ and Orntoft TF: Bladder squamous cell carcinomas express psoriasin and externalize it to the urine. J Urol 155: 2105-2112, 1996.

15. Hu M, Ye L, Ruge F, Zhi X, Zhang L and Jiang WG: The clinical significance of Psoriasin for non-small cell lung cancer patients and its biological impact on lung cancer cell functions. BMC Cancer 12: 588, 2012.

16. Enerbäck C, Porter DA, Seth P, Sgroi D, Gaudet J, Weremowicz S Morton CC, Schnitt S, Pitts RL, Stampl J, et al: Psoriasin expression in mammary epithelial cells in vitro and in vivo. Cancer Res 62: 43-47, 2002 .

17. Emberley ED, Alowami S, Snell L, Murphy LC and Watson PH: S100A7 (psoriasin) expression is associated with aggressive features and alteration of Jab1 in ductal carcinoma in situ of the breast. Breast Cancer Res 6: R308-R315, 2004

18. Watson PH, Leygue ER and Murphy LC: Psoriasin (S100A7). Int J Biochem Cell Biol 30: 567-571, 1998.

19. Shubbar E, Vegfors J, Carlström M, Petersson S and Enerbäck C: Psoriasin (S100A7) increases the expression of ROS and VEGF and acts through RAGE to promote endothelial cell proliferation. Breast Cancer Res Treat 134: 71-80, 2012.

20. Sneh A, Deol YS, Ganju A, Shilo K, Rosol TJ, Nasser MW and Ganju RK: Differential role of psoriasin (S100A7) in estrogen receptor $\alpha$ positive and negative breast cancer cells occur through actin remodeling. Breast Cancer Res Treat 138: 727-739, 2013.

21. Jemal A, Siegel R, Ward E, Hao Y, Xu J and Thun MJ: Cancer statistics, 2009. CA Cancer J Clin 59: 225-249, 2009.

22. Gadiya M, Mori N, Cao MD, Mironchik Y, Kakkad S, Gribbestad IS, Glunde K, Krishnamachary B and Bhujwalla ZM: Phospholipase D1 and choline kinase- $\alpha$ are interactive targets in breast cancer. Cancer Biol Ther 15: 593-601, 2014

23. Zuker M: Mfold web server for nucleic acid folding and hybridization prediction. Nucleic Acids Res 31: 3406-3415, 2003.

24. Bonnekoh B, Wevers A, Jugert F, Merk H and Mahrle G: Colorimetric growth assay for epidermal cell cultures by their crystal violet binding capacity. Arch Dermatol Res 281: 487-490, 1989.
25. Moffitt RA, Marayati R, Flate EL, Volmar KE, Loeza SG, Hoadley KA, Rashid NU, Williams LA, Eaton SC, Chung AH, et al: Virtual microdissection identifies distinct tumor- and stroma-specific subtypes of pancreatic ductal adenocarcinoma. Nat Genet 47: 1168-1178, 2015.

26. Zhang G, He P, Tan H, Budhu A, Gaedcke J, Ghadimi BM, Ried T, Yfantis HG, Lee DH, Maitra A, et al: Integration of metabolomics and transcriptomics revealed a fatty acid network exerting growth inhibitory effects in human pancreatic cancer. Clin Cancer Res 19: 4983-4993, 2013.

27. Deer EL, González-Hernández J, Coursen JD, Shea JE, Ngatia J, Scaife CL, Firpo MA and Mulvihill SJ: Phenotype and genotype of pancreatic cancer cell lines. Pancreas 39: 425-435, 2010.

28. Emberley ED, Niu Y, Leygue E, Tomes L, Gietz RD, Murphy LC and Watson PH: Psoriasin interacts with Jab1 and influences breast cancer progression. Cancer Res 63: 1954-1961, 2003.

29. Tomoda K, Kubota Y and Kato J: Degradation of the cyclindependent-kinase inhibitor $\mathrm{p} 27^{\mathrm{Kip} 1}$ is instigated by Jab1. Nature 398: 160-165, 1999.

30. Sgambato A, Cittadini A, Faraglia B and Weinstein IB: Multiple functions of p27(Kip1) and its alterations in tumor cells: A review. J Cell Physiol 183: 18-27, 2000.

31. Ellenrieder V, Alber B, Lacher U, Hendler SF, Menke A, Boeck W, Wagner M, Wilda M, Friess H, Büchler M, et al: Role of MT-MMPs and MMP-2 in pancreatic cancer progression. Int J Cancer 85: 14-20, 2000.

32. Zhang K, Chen D, Jiao X, Zhang S, Liu X, Cao J, Wu L and Wang D: Slug enhances invasion ability of pancreatic cancer cells through upregulation of matrix metalloproteinase- 9 and actin cytoskeleton remodeling. Lab Invest 91: 426-438, 2011.

33. Morgan MR, Jazayeri M, Ramsay AG, Thomas GJ, Boulanger MJ, Hart IR and Marshall JF: Psoriasin (S100A7) associates with integrin $\beta 6$ subunit and is required for $\alpha v \beta 6$-dependent carcinoma cell invasion. Oncogene 30: 1422-1435, 2011.

34. Dey KK, Sarkar S, Pal I, Das S, Dey G, Bharti R, Banik P Roy J, Maity S, Kulavi I, et al: Mechanistic attributes of S100A7 (psoriasin) in resistance of anoikis resulting tumor progression in squamous cell carcinoma of the oral cavity. Cancer Cell Int 15: $74,2015$. International (CC BY-NC-ND 4.0) License. 